\title{
KONSELING IBU HAMIL PADA BIDAN PRAKTIK SWASTA DAN PUSKESMAS DI KABUPATEN BANTUL
}

\author{
COUNSELING FOR PREGNANT WOMENAT MIDWIFE PRACTICEAND \\ COMMUNITY HEALTH CENTER AT BANTUL DISTRICT \\ Retno Heru' ${ }^{1}$, Mubasysyir Hasanbasri², Mohammad Hakimi ${ }^{2}$ \\ ${ }^{1}$ Akademi Kebidanan Yogyakarta, Yogyakarta \\ 2Program Studi IImu Kesehatan Masyarakat, Fakultas Kedokteran, \\ Universitas Gadjah Mada, Yogyakarta
}

\begin{abstract}
Background: One of the factors of Maternal and Neonatal Mortality is the lack of knowledge on the cause and how to deal with important complications during pregnancy, labor, and post natal. Counseling is an effort to dig and give useful information in order to help pregnant mother to take decisions. Midwife practice and Community Health Center is an organization which aims at giving service to pregnant mother including counseling. Midwife practice an independent organization which is managed privately, whereas Community Health Center is an organization which belongs and runs by the government.

Objectives: The objective of the research is to find out the implementation of counseling on pregnant mother which includes, time, places, instruments, materials, problem solving, training efforts, and form of teaching counseling skill on midwife practice and Community Health Center in Bantul district.

Method: Research method used in this research is qualitative research method with case study and descriptive method. The analysis unit is the pregnant mother, midwife in charge in midwife practice and in Community Health Center. The data was taken using purposive sampling through interview, observation and library study.

Result: Counseling implementation in midwife practice and Community Health Service is done through giving information. The time done for counseling is under the standard which was below 20 minutes. The counseling process is undergone in one place along with the other services, and there are many patients in the room. The instruments used for counseling is just KIA book and there are no other instruments, the information given is merely on the problems which are shared by the pregnant mother. If the pregnant mother doesn't share her problem, the midwife will not give counseling. The problem which is often faced by the midwife is that pregnant mother has difficulties in intrepreting information given. Problem solving is done through the participation of the husband during the counseling service. Training efforts to increase the counseling skill has not been done officially. The efforts taken so far is by reading books or learn from other coleagues. The form of teaching counseling skill is using roleplay, done in pairs and not more than 45 minutes.

Conclusion: The implementation of counseling for pregnant mother is done inappropriately, which is not the same as it is stated in the Standart Service of Midwifery. It makes pregnant mother doesn't have the necessary information dealing with the pregnancy.
\end{abstract}

Keywords: Counseling, Pregnancy, Midwife

\section{ABSTRAK}

Latar Belakang: Salah satu penyebab tingginya Angka Kematian Bayi dan Angka Kematian Ibu adalah karena kurangnya pengetahuan tentang penanggulangan dan komplikasi-komplikasi penting dalam kehamilan, persalinan, dan nifas. Konseling adalah upaya menggali dan memberikan informasi guna mendapatkan apa yang dibutuhkan dan membantu ibu hamil dalam mengambil keputusan. Bidan Praktik Swasta dan Puskesmas adalah organisasi pelayanan kesehatan yang memberikan pelayanan pada ibu hamil termasuk konseling. BPS adalah organisasi pelayanan kesehatan swasta yang dikelola secara mandiri, sedangkan Puskesmas adalah organisasi pelayanan kesehatan yang di kelola oleh pemerintah.

Tujuan: Tujuan penelitian ini adalah untuk mengetahui pelaksanaan konseling pada ibu hamil yang meliputi: praktik konseling, waktu, tempat, alat bantu, materi, cara mengatasi hambatan, upaya peningkatan ketrampilan, dan bentuk pengajaran ketrampilan konseling di pendidikan di BPS dan puskesmas di Kabupaten Bantul.

Metode: Metode penelitian adalah metode kualitatif dengan rancangan studi kasus dan bersifat deskriptif. Unit analisis adalah ibu hamil, bidan pelaksana di BPS dan puskesmas. Data diambil secara purposive sampling melalui wawancara mendalam dan lembar pengamatan konseling serta penelusuran dokumen.

Hasil: Praktik konseling di BPS dan puskesmas dalam bentuk pemberian informasi. Waktu yang digunakan dalam proses konseling masih kurang yaitu di bawah 20 menit. Tempat yang digunakan untuk proses konseling menjadi satu dengan tempat yang digunakan untuk periksa kehamilan, dan banyak orang yang ada dalam ruangan periksa. Alat bantu yang digunakan untuk konseling sebatas buku KIA dan belum menggunakan alat bantu yang lain. Informasi yang diberikan sebatas pada keluhan yang disampaikan oleh ibu hamil. Jika ibu hamil tidak menyampaikan keluhan, bidan tidak berusaha menggali permasalahan atau memberikan informasi. Hambatan yang paling sering ditemui bidan adalah sulitnya ibu hamil memahami informasi yang diberikan bidan. Cara penyelesaian hambatan dengan cara melibatkan suami dalam proses konseling. Upaya peningkatan ketrampilan konseling secara resmi seperti pelatihan-pelatihan belum ada. Upaya yang dilakukan selama ini adalah dengan membaca buku-buku dan belajar dari teman. Bentuk pengajaran ketrampilan konseling di pendidikan dengan metode roleplay, dilaksanakan dikelas, dan dilakukan dengan teman sendiri.

Kesimpulan: Proses konseling pada ibu hamil yang dilakukan oleh bidan pada umumnya tidak berjalan sebagaimana mestinya, yaitu tidak sesuai dengan pedoman yang ada dalam standart 
pelayanan kebidanan. Dampaknya adalah ibu hamil belum paham dengan segala hal yang berkaitan dengan kehamilan.

Kata Kunci: Konseling, Kehamilan, Bidan

\section{PENGANTAR}

Pada kehamilan terdapat perubahan pada seluruh tubuh wanita, khususnya pada alat genetalia eksterna dan interna ${ }^{1}$. Kehamilan juga memberikan perubahan baik secara fisiologis maupun psikologis bagi ibu hamil, sehingga setiap wanita hamil menghadapi resiko komplikasi yang bisa mengancam jiwanya. Identifikasi risiko, pendidikan kesehatan atau nasehat, dorongan mental kepada ibu hamil dan pemeriksaan yang efektif untuk mengidentifikasi masalah kehamilan tersebut dapat diselesaikan dan keahlian komunikasi merupakan kunci penyelesaian masalah. Hal tersebut dapat dibantu dengan konseling ${ }^{2}$.

Bidan merupakan tenaga penyedia pelayanan pemeriksaan kehamilan mayoritas di Indonesia. Bidan mempunyai tugas penting dalam konseling dan pendidikan kesehatan, tidak hanya kepada perempuan, tetapi juga kepada keluarga dan masyarakat. Kegiatan ini harus mencakup pendidikan antenatal dan persiapan menjadi orang tua serta dapat meluas pada kesehatan perempuan, kesehatan seksual atau kesehatan reproduksi dan asuhan anak ${ }^{3}$.

Bidan dapat praktik diberbagai tatanan pelayanan, termasuk dirumah, di masyarakat, di rumah sakit, klinik atau unit pelayanan kesehatan lainnya. Bidan Praktik Swasta (BPS) adalah unit pelayanan kesehatan swasta yang dikelola secara mandiri, sedangkan puskesmas adalah unit pelayanan kesehatan yang dikelola oleh pemerintah. Organisasi pelayanan kesehatan seperti rumah sakit dan puskesmas, praktek dokter dan apotek, laboratorium adalah organisasi pelayanan kesehatan sebagai pelayanan masyarakat perlu memiliki karakter mutu pelayanan prima yang sesuai dengan harapan pasien, selain diharapkan memberikan pelayanan medis yang bermutu ${ }^{4}$.

Konseling sebagai bagian dari pelayanan kebidanan perlu suatu manajemen yang baik. Tercapainya tujuan tersebut tidak lepas dari perencanaan dan pengorganisasian yang merupakan bagianbagian dari manajemen. Agar proses konseling berkualitas, bidan perlu mempunyai pengetahuan dan ketrampilan tentang konseling. Upaya meningkatkan kualitas pelayanan kebidanan juga ditentukan oleh ketrampilan bidan untuk berkomunikasi secara efektif dan melakukan konseling yang baik kepada klien.

\section{BAHAN DAN CARA PENELITIAN}

Jenis penelitian yang dilakukan adalah penelitian deskriptif kualitatif dengan menggunakan studi kasus sebagai pendekatannya untuk menggambarkan pelaksanaan konseling pada ibu hamil pada Bidan Praktik Swasta (BPS) dan puskesmas ${ }^{5}$. Lokasi penelitian di BPS Siti Boinah Basuki dan Puskesmas Sewon II Kabupaten Bantul Provinsi Daerah Istimewa Yogyakarta. Penelitian ini dilakukan dengan wawancara mendalam di BPS dan puskesmas. Wawancara mendalam dilakukan terhadap Bidan pelaksana dan ibu hamil yang memeriksakan kehamilannya. Analisis data dengan menggunakan teknik penjelasan yaitu menjelaskan hasil wawancara dan analisis cheklist hasil observasi serta analisis hasil penelusuran dokumen ${ }^{6}$.

\section{HASIL PENELITIAN DAN PEMBAHASAN}

Berdasarkan hasil penelitian, bentuk praktik konseling pada ibu hamil di Bidan Praktik Swasta (BPS) dan Puskesmas adalah dengan memberikan penjelasan atau informasi pada ibu hamil. Metode pemberian informasi ini dilakukan dengan cara komunikasi 2 arah antara bidan dengan ibu hamil. Pada prakteknya pemberian informasi pada ibu hamil di BPS dan Puskesmas agak sedikit berbeda.

Bidan Praktik Swasta (BPS) memberikan informasi lebih lengkap dibandingkan dengan informasi yang diberikan oleh bidan di puskesmas. Informasi yang diberikan pada trimester I atau pada kunjungan awal biasanya lebih banyak dari pada kunjungan ulang. Pada kunjungan ulang informasi yang diberikan hanya berdasarkan pada keluhan ibu hamil. Bidan di BPS menyadari bahwa ibu hamil belum tentu mengetahui tentang kehamilannya sehingga setiap ibu hamil yang datang memeriksakan kehamilannya diberikan informasi.

Informasi yang diberikan pada ibu hamil oleh bidan di puskesmas pada trimester awal ditekankan pada larangan-larangan selama hamil muda. Pada kunjungan ulang, bidan memberikan informasi berdasarkan keluhan ibu hamil saja. Hal-hal yang menyebabkan terjadinya keluhan tidak dijelaskan secara rinci oleh bidan tetapi hanya sebatas pada cara mengatasi keluhan. Hal tersebut dirasakan masih sangat kurang oleh ibu hamil.

Kehamilan dapat menimbulkan komplikasi yang dapat mengancam jiwa ibu maupun bayi sehingga di dalam setiap kunjungan antenatal ibu hamil perlu mendapatkan informasi-informasi penting tentang kehamilannya agar dapat diidentifikasi sedini mungkin adanya komplikasi. Either ${ }^{7}$ mengatakan bahwa 
identifikasi komplikasi pada ibu hamil dapat dilakukan dengan konseling selama kehamilan. Hal ini didukung oleh Obermeyer ${ }^{8}$ yang mengatakan bahwa konseling yang diberikan dalam bentuk informasi dapat membantu klien dalam mengenali resiko yang ada dalam dirinya, meskipun pada pelaksanaannya belum sempurna, tetapi pemberian informasi sebagai bentuk pelaksanaan konseling yang dilakukan di BPS maupun puskesmas sudah cukup membantu ibu hamil dalam memahami perubahan yang terjadi selama kehamilan dan kebutuhan dirinya.

Tidak ada pedoman waktu untuk proses konseling, baik di BPS maupun puskesmas. Konseling biasanya sudah termasuk dalam pelayanan kehamilan yang meliputi: anamnesis, pemeriksaan fisik, dan KIE/konseling. Waktu yang digunakan dalam melakukan proses konseling oleh bidan di puskesmas 5-10 menit, sedangkan bidan di BPS membutuhkan waktu 10 menit untuk konseling 1 ibu hamil. Waktu yang singkat, bidan tidak sempat menggali lebih jauh permasalahan ibu hamil dan ibu hamil tidak bisa mengungkapkan semua permasalahannya.

Salah satu hambatan dalam proses konseling adalah waktu yang dimiliki konselor terbatas ${ }^{9}$. Ibu hamil dengan tingkat pendidikan menengah (SMA) dan pengetahuan tentang kehamilan rendah sangat membutuhkan informasi secara menyeluruh, tidak hanya setengah-setengah. Waktu konseling yang bersamaan dengan pemeriksaan kehamilan tidak tepat, karena banyak hal yang menghalangi terlaksananya proses konseling yang baik. Meminta kesediaan waktu yang khusus dapat menimbulkan kenyamanan dalam berkomunikasi dibandingkan dengan melakukan komunikasi ditengah kesibukan. Penyesuaian waktu yang tepat saat menyampaikan informasi atau berkomunikasi, orang yang menerima informasi akan lebih mendengarkan atau memperhatikan apa yang disampaikan.

Banyak hal yang mempengaruhi konseling, entah konseling itu menjadi lancar atau sebaliknya. Seorang bidan dalam melakukan konseling hendaknya memperhatikan tempat dimana konseling dilakukan. Ruang pemeriksaan ibu hamil di BPS menjadi satu dengan ruang yang digunakan untuk konseling dan ruang pemeriksaan ibu hamil di puskesmas. Ruang periksa ada empat orang atau lebih. Bidan harus menggunakan fasilitas tersebut karena fasilitas tersebut bukan miliknya, tetapi milik pemerintah. Untuk kelengkapan perabot maupun perluasan ruangan mereka tergantung pada pemerintah.

Kondisi ruangan tersebut bukan merupakan tempat yang tepat untuk melakukan konseling. Suasana yang bising, tidak ada privasi yang tepat, akan kerancuan, ketegangan, dan ketidaknyamanan. Konseling biasanya berlangsung dalam suasana ramai. Tempat tersebut tidak bisa memberikan jaminan terhadap privasi ibu hamil karena pembicaraan mudah didengar orang lain. Gangguan yang lain, karyawan yang lain mudah sekali keluar masuk sehingga mengganggu proses konseling. Hal tersebut juga disampaikan oleh responden ibu hamil, bahwa ruangan tersebut tidak nyaman dan tidak mampu melindungi privasinya. Ada perasaan tidak enak saat menerima pelayanan. Keadaan tersebut bertentangan dengan apa yang disampaikan oleh Tyastuti ${ }^{9}$ yaitu bahwa situasi selama melakukan komunikasi sangat mempengaruhi keberhasilan komunikasi, lingkungan yang tenang dan terjaga privasinya merupakan situasi yang sangat mendukung.

Menurut Uripni ${ }^{4}$ penggunaan alat bantu seperti poster dan gambar-gambar sangat menolong bidan dalam memberikan penjelaskan pada ibu hamil. Pesan atau informasi yang disampikan sebaiknya menggunakan media atau alat bantu komunikasi yang tersedia, karena pada umumnya ibu hamil berpendidikan menengah dan belum paham benar tentang kehamilan. Kenyataannya, dalam melaksanakan konseling bidan tidak selalu menggunakan media atau alat bantu. Hanya buku KIA yang pernah digunakan dan kadang-kadang jika ada brosur menggunakan brosur. Manfaat media ini adalah untuk menimbulkan minat, mengatasi hambatan bahasa, mempermudah penerimaan informasi oleh sasaran yang pada akhirnya akan merangsang sasaran untuk melaksanakan pesan-pesan kesehatan ${ }^{10}$.

Dalam proses konseling, bidan tidak pernah menggunakan panduan konseling, baik panduan dalam melakukan proses konseling maupun pedoman pelayanan kebidanan dasar, alasannya adalah dengan bekal praktek selama lebih dari 10 tahun, bidan merasa sudah bisa melakukan proses konseling. Menurut Depkes $\mathrm{RI}^{11}$, seharusnya dalam memberikan pelayanan ANC kepada ibu hamil mengacu pada item-item yang ada di dalam buku-buku tersebut.

Hasil penelitian menunjukkan bahwa informasi yang disampaikan oleh bidan biasanya hanya sebatas respon terhadap keluhan yang disampaikan oleh ibu hamil, tidak mencakup keseluruhan yang dibutuhkan oleh ibu hamil. Pesan yang disampaikan seharusnya bukan hanya atas dasar keluhan dari ibu hamil, tetapi berdasarkan kebutuhan dan kepentingan bagi seorang yang sedang hamil, sehingga pesan yang disampaikan oleh bidan tidak bisa diterima dengan baik. Banyak hal yang belum dipahami oleh ibu hamil. Menurut Widjaya ${ }^{12}$, bahwa pesan yang disampaikan harus tepat dan mengena yang meme- 
nuhi syarat diantaranya adalah jelas dan gamblang dengan bahasa yang jelas, seimbang, serta sesuai dengan kepentingan komunikan. Metode konseling yang dipilih oleh bidan tidak dipraktekkan dengan sistematis, tidak sesuai dengan petunjuk konseling ibu hamil, yang meliputi: memberi salam, menanyakan, menguraikan, membantu, menjelaskan, dan mengulangi informasi. Informasi tidak disampaikan secara rinci, hanya berupa informasi singkat tentang cara mengatasi keluhan ibu hamil.

Hambatan yang paling sering ditemui adalah pengetahuan ibu hamil masih rendah, sehingga sulit menerima informasi yang diberikan bidan. Untuk mengatasi hal tersebut, bidan melibatkan suami dalam pemberian informasi, atau memberikan brosur untuk dibawa pulang dengan harapan brosur bisa dibaca di rumah oleh ibu hamil. Salah satu faktor yang mempengaruhi proses konseling adalah pengetahuan, baik tingkat pengetahuan bidan maupun ibu hamil. Bidan perlu mengetahui tingkat pengetahuan klien sehingga dapat berinteraksi dengan baik dan akhirnya dapat memberi asuhan kebidanan yang tepat kepada klien ${ }^{4}$.

Bidan merasa bahwa konseling pada ibu hamil dianggap tidak begitu penting seperti halnya pelatihan Asuhan Persalinan Normal (APN), sehingga bidan yang ada di BPS maupun puskesmas merasa pelatihan konseling kehamilan tidak pernah dilakukan. Padahal menurut Yulifah ${ }^{13}$, konseling kebidanan adalah proses pembelajaran, pembinaan hubungan baik, pemberian bantuan, dan bentuk kerjasama yang dilakukan secara profesional sesuai dengan bidangnya oleh bidan kepada klien untuk memecahkan masalah, mangatasi hambatan perkembangan, dan memenuhi kebutuhan klien. Persiapan untuk persalinan, perlu diberikan informasi dan pendampingan konseling yang dapat mendukung ibu dalam persalinan sehingga perasaan takut dapat dikurangi serta ibu dapat mempertahankan kontrol emosinya dengan baik, yaitu konseling pada persalinan maupun pada kehamilan sama pentingnya agar ibu lebih memahami dirinya dan dapat membuat keputusan yang tepat.

Bentuk pengajaran praktikum dilaksanakan di kelas dengan metode rollplay. Metode rollplay adalah bermain peran. Dosen memberikan kasus-kasus kebidanan, dan mahasiswa bermain peran menyelesaikan kasus dengan konseling. Praktikum dilaksanakan sesama teman, dan tidak pada pasien langsung. Menurut responden bidan, hal tersebut tidak serius karena dilakukan dengan sesama teman. Akan lebih baik jika praktikum dilaksanakan pada pasien ibu hamil langsung. Pelaksanaan rollplay dilakukan da- lam waktu yang singkat. Setiap kelompok tidak sama, yaitu ada yang 15 menit sudah selesai dan ada yang 30 menit baru selesai. Waktu yang dialokasikan dosen 1 kelompok adalah 45 menit. Hal tersebut dirasakan masih kurang oleh responden bidan. Perlu penambahan waktu rollplay dan kasus, sehingga akan lebih paham. Hal tersebut sesuai dengan apa yang disampaikan oleh Notoadmodjo ${ }^{10}$, pengetahuan tidak hanya disekolah tetapi juga bisa dari pengalaman. Dalam hal ini pengalaman yang dimaksud adalah pengalaman praktik konseling yang menggunakan pasien langsung.

\section{KESIMPULAN DAN SARAN}

Proses konseling pada ibu hamil yang dilakukan oleh bidan pada umumnya tidak berjalan sebagaimana mestinya, yaitu tidak sesuai dengan pedoman yang ada dalam standart pelayanan kebidanan. Dampaknya adalah ibu hamil belum paham dengan segala hal yang berkaitan dengan kehamilan. Beberapa komponen dalam proses konseling pada ibu hamil yang menjadi fokus penelitian ini belum dilaksanakan sepenuhnya oleh bidan. Komponen tersebut antara lain: 1) praktik konseling di puskesmas maupun BPS dilakukan dalam bentuk pemberian informasi berdasarkan keluhan yang dirasakan ibu hamil dan berdasarkan kebutuhan tiap trimester. 2) waktu yang digunakan dalam proses konseling masih kurang yaitu masih di bawah 20 menit. 3) tempat yang digunakan untuk proses konseling dinilai responden ibu hamil belum cukup nyaman, karena ruangan ramai dan tidak nyaman untuk menyampaikan keluhan-keluhan, 5) alat bantu yang digunakan dalam proses konseling hanya buku KIA yang digunakan, kadangkadang menggunakan poster. 6) informasi yang disampikan bidan sebatas menjawab keluhan ibu hamil saja, sehingga masih banyak informasi yang belum diberikan pada ibu hamil, 7) hambatan yang paling sering ditemui adalah tingkat pendidikan ibu hamil rendah sehingga sulit menerima informasi., 8) upaya peningkatan ketrampilan konseling dengan cara mambaca buku-buku tentang konseling dan tentang kehamilan, belajar dari teman, dan belajar dari pengalaman selama praktik menjadi bidan,. dan 9) bentuk pengajaran konseling di pendidikan adalah dengan teori dan praktikum dengan metode rollplay..

\section{SARAN}

Pemberian informasi sebaiknya tidak hanya berdasar pada keluhan ibu hamil saja tetapi menyeluruh sesuai tahap perkembangan dalam kehamilan, sehingga ibu hamil akan lebih memahami tentang kehamilannya. Waktu yang digunakan dalam proses 
konseling sebaiknya sesuai dengan teori yang ada yaitu 20 menit, supaya informasi yang disampaikan lebih jelas. Tempat yang digunakan untuk proses konseling adalah ruangan yang tersendiri yang memberikan rasa nyaman pada ibu hamil sehingga ibu hamil dapat menyampaikan permasalahannya tanpa rasa malu atau takut terdengar oleh orang lain. Alat bantu yang digunakan dalam proses konseling adalah tidak hanya buku KIA yang digunakan, tetapi menggunakan media lain seperti poster dan lembar balik sehingga dapat mempermudah penyampaian informasi kepada ibu hamil. Bentuk pengajaran praktikum tentang konseling adalah dilakukan dengan pasien langsung, di ruang laboratorium dengan sarana yang memadai, dan dilakukan umpan balik setelah selesai rollplay.

\section{REFERENSI}

1. Wiknjosastro, Ilmu Kebidanan, Penerbit Yayasan Bina Pustaka Sarwono Prawirohardjo. Jakarta, 2007.

2. The Board of Trustees of The University of Illionis, Prenatal Care Information and Resources. McKinley Health Center, 2005

3. Keputusan Menteri Kesehatan RI Nomor 369/ MENKES/SK/III/2007, Tentang Standart Profesi Bidan, Jakarta, 2007.

4. Uripni, Komunikasi Kebidanan, Penerbit EGC, Jakarta, 2003.

5. Yin, Robert K, Studi Kasus Desain dan Metode, PT Raja Grafindo Persada, Jakarta, 2006.
6. Blaxter L, Hughter C, Thigt M, How to ReSearch; Seluk Beluk Melakukan Riset. Edisi Kedua, PT Indeks Kelompok Gramedia, 2001.

7. Kathleen AE, Rachel Fox-Tierney BS, William C, Kathryn MS, Jeannette RI, Organizational Predictors of Prenatal HIV Counseling and Testing, American Journal of Publich Health, 2000;90(9), http://ajph.aphapublications.org> [diakses tanggal 3 April 2011].

8. Obermeyer CM, Michelle O, (2000). The Utilization of Testing and Counseling for HIV:A Review of the Social and Behavioral Evidence. American Journal of Public Health, 2000;97(10), $<$ http://ajph.aphapublications.org> [diakses tanggal 3 April 2011].

9. Tyastuti S, Kusmiyarti Y, Handayani S, Komunikasi dan Konseling dalam Pelayanan Kebidanan, Penerbit Fitramaya, Yogyakarta, 2008.

10. Notoadmojo S,Pendidikan dan Perilaku Kesehatan, Penerbit Rineka Cipta. Jakarta, 2003.

11. Departemen Kesehatan R.I, Panduan Bidan di Tingkat Desa. Penerbit Dep.Kes. R.I, Ditjen PKM, Direktorat Bina Kesehatan Keluarga. Jakarta, 1998.

12. Widjaya HAW, IImu Komunikasi Pengantar Studi, Penerbit Rineka Cipta. Jakarta, 2000.

13. Yulifah, Komunikasi dan Konseling dalam Kebidanan, Penerbit Salemba Medika, Jakarta, 2009. 